http://jmscr.igmpublication.org/home/ ISSN (e)-2347-176x ISSN (p) 2455-0450 crossref DOI: https://dx.doi.org/10.18535/jmscr/v8i6.04

\title{
Does choice of mechanical prosthetic valve affect change in left ventricular functions after aortic valve replacement
}

Authors

\section{Hakeem Zubair Ashraf*, Nadeem-ul-Nazeer, Abdul Gani Ahangar, Farooq A Ganie, Mohammad, Yaqoob Khan, Haroon Rashid Naqshi, Abdul Majeed Dar, Mohammad Akbar Bhat, Syed Mohsin, Peerzada Hidayat, Pradeep Kumar, Rouf Gul}

Department of CVTS, Sher-i-Kashmir Institute of Medical Sciences (SKIMS) Soura, Srinagar, Kashmir, India, 190011

*Corresponding Author

Dr Hakeem Zubair Ashraf (MCh.)

\begin{abstract}
Background: We sought to determine whether the choice of mechanical prosthetic valve (Bileaflet or Monoleaflet) has any effect on change in left ventricular functions and valve gradients after aortic valve replacement (AVR) in patients with pure aortic valve disease.

Methods: Eighty two patients were included in the study who underwent aortic valve replacement for isolated aortic valve disease using either a bileaflet (Group1) or a monoleaflet valve (Group 2). The measurements included Left Ventricular End-Diastolic (LVEDd) and Left Ventricular End-Systolic (LVEDs) dimensions and Left Ventricular End-Diastolic (LVEDV) and Left Ventricular End-Systolic (LVESV) volumes, Ejection Fraction (EF), Stroke Volume (SV), NYHA class and Cardiac Output (CO). Comparisons of different parameters were made in two groups to determine the significance of choice of prosthetic valve.

Results: Aortic valve replacement induces a favourable remodeling of the left ventricle and a significant improvement in left ventricular functions. There was no statistically significant difference in the measured parameters between the two groups and hence choice of prosthetic valve does not influence the outcome.

Conclusion: Impaired cardiac functions show significant improvement after AVR. Functional class was improved or maintained in all the patients in both the groups. Left ventricular systolic pump functions were improved in almost all the patients, comparable in both the groups.
\end{abstract}

\section{Introduction}

The normal aortic orifice measures 2.5 to $3 \mathrm{~cm}^{2}$. Any alteration in the size of the valve produces variety of haemodynamic changes from either stenotic, regurgitant or combined lesions. Stenosis causes mechanical obstruction of the left ventricular outflow leading to increase in the gradient across the aortic valve.
This then leads to systolic hypertension in the left ventricle which is compensated by concentric hypertrophy of the left ventricle which becomes stiff with reduced compliance. Thus to maintain cardiac output a higher left ventricular end diastolic pressure is required. A combination of LV hypertrophy, decreased LV compliance and longer systolic ejection 
time leads to increase in myocardial oxygen demand. Increased ventricular wall tension in turn reduces coronary blood flow with chronic ischemia. With further decrease in the aortic valve size there is increase in the gradient across the valve with subsequent angina, syncope and congestive cardiac failure.

In contrast to increase in $\mathrm{LV}$ end diastolic pressure in aortic stenosis, aortic regurgitation causes an increase in the end diastolic volume in LV for haemodynamic compensation. There is subsequent dilatation of the left ventricle to support a large stroke volume causing an increase in myocardial oxygen demand. There is insidious increase in ventricular muscle mass surpassing that seen in aortic stenosis. These patients do initially respond to medical measures but generally require valve replacement at later stage. Syncope, angina and heart failure constitute the indications for the aortic surgery in aortic stenosis with angina being the most common symptom. The symptoms are evident when the valve area decreases below $1 \mathrm{~cm}^{2}$ and gradient across the valve is more than $50 \mathrm{mmHg}$. Aortic insufficiency in contrast has more complex indications and are driven by NYHA functional class more often than by the gradient across the valve or valve area. In general, therefore, for I and II NYHA Functional class, valve replacement is indicated only with left ventricular dysfunction, a cardio thoracic ratio of greater than 0.55 or LV end diastolic dimensions of more than $50 \mathrm{~mm}$. For III and IV functional class surgery is indicated even in absence of ventricular dysfunction.

Post Aortic Valve Replacement (AVR) either using a mechanical or a bioprosthetic valve pressure gradients still occur across the valve with the magnitude of gradient depending upon the size of the valve relative to the body surface area, characteristics of the prosthesis and the required cardiac output. This can very accurately be determined by echocardiography. Echocardiography thus has developed as an excellent means of assessing left ventricular functions.

We sought to determine whether the choice of prosthetic valve has any effect on change in left ventricular functions and valve gradients before and after aortic valve replacement (AVR) in patients with pure aortic valve disease over last 10 years in our institute using a Bileaflet and a Monoleaflet mechanical valves.

\section{Materials and Methods}

Eighty two patients were included in the study retrospectively who underwent aortic valve replacement for isolated aortic valve disease in our department from August 2007 to March 2020. We compared two types of mechanical valves - Bileaflet (Group 1) and Monoleaflet (Group 2) and included only those patients who had mechanical prosthetic aortic valve of sizes above $21 \mathrm{M}$ implanted. M-mode and 2-D echocardiograms done one year after aortic valve replacement were studied and compared. Patients of both sexes were included. Body surface area and rough estimate of cardiac output of all patients was noted. The measurements included Left Ventricular Internal Diameter in Diastole (LVIDd), Left Ventricular Internal Diameter in Systole (LVIDs), Left Ventricular End-Diastolic (LVEDV) and Left Ventricular End-Systolic (LVESV) volumes , Ejection Fraction (EF), Stroke Volume (SV) and Cardiac Output (CO). Gradients across the valve were also measured. Patients with both degenerative and rheumatic aortic valve disease were selected. Traumatic valve lesions were excluded so were valve regurgitations caused due to aortic dissection. Postoperatively, each patient was placed on a mild warfarin anticoagulation regimen, which was adjusted every three weeks according to the prothrombin time and International Normalized Ratio (INR). Both intergroup and intra group comparisons of different parameters were made to 
determine the significance of choice of prosthetic valve.

\section{Statistical Analysis}

Statistical analysis was performed using students t-test to detect significant differences between measured variables. Continuous variables were expressed as mean \pm standard deviation. Categorical variables expressed as percentage, were analysed using Fisher's exact test. A p-value less than 0.05 was considered statistically significant.

\section{Results}

\section{Group1: (Table 1,2,3)}

There were 51 patients. Male female ratio was 2 . Most of the patients were in the age group of 30- 40 . Mean age was $40.35( \pm 8.85)$. Age range was 30-65 years. Eighteen patients had aortic stenosis, 10 had aortic regurgitation, and 23 had combined stenosis and regurgitation. Forty one patients had rheumatic valve affection while 10 had degenerative valve disease. Thirty three $(65 \%)$ of the patients belonged to functional class III. Eighteen (35\%) were in functional class II and none in class I and IV.

Patients with aortic stenosis had their left ventricular internal diameters in diastole (LVIDd) significantly decreased to a postoperative mean of $4.5( \pm 0.07) \mathrm{cm}$ from a preoperative mean of $5.3( \pm 0.33) \mathrm{cm} ;(\mathrm{p}<0.035)$. Left ventricular internal diameters in systole (LVIDs) reduced from a mean of $3.6( \pm 0.23) \mathrm{cm}$ preoperatively to $2.9( \pm 0.30) \mathrm{cm}$ postoperatively; $(\mathrm{p}<0.04)$ which was significant. For patients who had aortic valve incompetence the LVIDd registered a decrease from a mean of $5.92( \pm 0.07) \mathrm{cm}$ preoperatively to $4.86 \quad\left(\begin{array}{lll} \pm & 0.41) \quad \mathrm{cm}\end{array}\right.$ postoperatively; $(\mathrm{p}<0.036)$ and LVIDs from mean of $4.78( \pm 0.32) \mathrm{cm}$ to $4.35( \pm 0.25) \mathrm{cm}$; $(\mathrm{p}<0.24)$ which were not significant. Patients with combined aortic valve lesions, LVIDd showed a decrease from $5.8( \pm 0.21)$ to 4.6 $( \pm 0.32) ;(\mathrm{p}<0.0032)$ and LVIDs from $4.54( \pm$ $0.17)$ to $2.87( \pm 0.25) ;(\mathrm{p}<0.004)$. Overall in all patients of Gp1 LVIDd was reduced to a mean of $4.35( \pm 0.13) \mathrm{cm}$ postoperatively from a mean of $5.86( \pm 0.22) \mathrm{cm}$ preoperatively $;(\mathrm{p}<0.001)$. LVIDs reduced from a mean of $3.86( \pm 0.21) \mathrm{cm}$ to a mean of $3.03( \pm 0.13) \mathrm{cm}$; $(\mathrm{p}<0.001)$.

An important parameter to determine preload and ejection fraction is Left Ventricular End Diastolic volume (EDV) and End Systolic Volumes (ESV). In patients with aortic stenosis the preoperative EDV of a mean of $140(\underline{ \pm}$ 8.0) $\mathrm{ml}$ had decreased to a postoperative value of $92( \pm 4.3) \mathrm{ml} ;(\mathrm{p}<0.04)$ while ESV decreased from a mean of $68( \pm 5.2) \mathrm{ml}$ to $52( \pm 3.3) \mathrm{ml}$; $(\mathrm{p}<0.037)$. In patients with aortic regurgitation end diastolic (EDV) decreased from a mean of $169( \pm 8.22) \mathrm{ml}$ preoperatively to a mean of $88( \pm 7.6) \mathrm{ml}$ postoperatively ; $(\mathrm{p}<0.001)$. ESV in these patients also decreased from a mean of $92( \pm 3.2) \mathrm{ml}$ preoperatively to $46( \pm 3.2) \mathrm{ml}$ postoperatively; $(\mathrm{p}<0.002)$. For patients with combined aortic stenosis and regurgitation EDV decreased to a mean of $89( \pm 5.1)$ mlfrom a preoperative mean of $166( \pm 6.7) \mathrm{ml} ;(\mathrm{p}<0.0003)$. ESV in these decreased from a preoperative mean of $79( \pm 4.1) \mathrm{ml}$ to a mean of $53( \pm 3.2) \mathrm{ml}$; $(\mathrm{p}<0.034)$. In all patients taken together the LVEDV showed a significant decrease from a mean value of $166( \pm 7.3) \mathrm{ml}$ to a mean of 93 $( \pm 5.1) \mathrm{ml} ; \quad(\mathrm{p}<0.0003)$ that was highly significant. LVESV also showed a significant decrease from a mean of $76.31( \pm 4.1) \mathrm{ml}$ to a postoperative value of $39( \pm 3.1) \mathrm{ml}$; $(\mathrm{p}<0.0001)$.

One of the widely accepted determinants of adequate ventricular function is the percentage of end diastolic blood volume ejected by the ventricle at the end of systole called the Ejection Fraction(EF). In patients who had aortic stenosis, EF increased from a preoperative mean of $48.3( \pm 2.3) \%$ to a value of $56.02( \pm 3.8) \%$ post AVR $(\mathrm{p}<0.013)$ which was significant. In patients with aortic regurgitation $\mathrm{EF}$ increased from a mean of $46.34( \pm 1.8) \%$ to $56.67( \pm 2.6) \% ;(\mathrm{p}<0.023)$. In patients with combined lesion EF increased to 
$62.05( \pm 2.1) \%$ from a preoperative mean of $53.27( \pm 3.4) \% ;(\mathrm{p}<0.0013)$. When all patients were studied together EF increased from $54.02( \pm 2.4) \%$ to $60.35( \pm 3.1) \% ;(\mathrm{p}<0.023)$.

In patients with aortic stenosis, mean stroke volume (SV) of $43.23( \pm 1.6) \mathrm{ml}$ rose to a mean of $47.45( \pm 2.2) \mathrm{ml}$ after replacement $;(\mathrm{p}<0.231)$. In those with $\mathrm{AR}$ as the only lesion, AVR caused a decrease of stroke volume from a preoperative mean of $91.6( \pm 1.7) \mathrm{ml}$ to a mean of $52.34( \pm 5.7) \mathrm{ml}$ with a $(\mathrm{p}<0.002)$ that was significant. In patients with combined lesions SV decreased from $87.24( \pm 3.81) \mathrm{ml}$ to $55.45( \pm 2.98) \mathrm{ml} ;(\mathrm{p}<0.00045)$. In all patients of Group1 taken together the SV before surgery showed a mean value of $88.79( \pm 4.2) \mathrm{ml}$ that decreased to $55.89( \pm 2.1) \mathrm{ml}$ after AVR $;(\mathrm{p}<0.004)$.

Cardiac output (CO) in patients with aortic stenosis decreased from a mean preoperative value of $3.8( \pm 0.12) \mathrm{L} / \mathrm{min}$ to a mean of $3.5( \pm$ $0.23) \mathrm{L} / \mathrm{min} ;(\mathrm{p}<0.135) \quad$ In isolated aortic regurgitation these values after AVR decreased from a mean of $6.97( \pm 0.23) \mathrm{L} / \mathrm{min}$ to a mean of $4.12( \pm 0.3) ; \mathrm{p}<0.036$ In combined lesions $\mathrm{CO}$ decreased from a preoperative mean value of $7.34( \pm 0.42) \mathrm{L} / \mathrm{min}$ to a postoperative mean of $4.45( \pm 0.12) \mathrm{L} / \mathrm{min} ;(\mathrm{p}<0.002)$. For all patients taken together the $\mathrm{CO}$ showed a significant decrease from a preoperative mean of $7.56( \pm 0.66) \mathrm{L} / \mathrm{min}$ to $4.54( \pm 0.43) \mathrm{L} / \mathrm{min}$ ; $(\mathrm{p}<0.0001)$.

There was an overall improvement in the functional class of the patients with most of patients having graduated from a higher class to lower class post AVR. Preoperatively, 33 $(65 \%)$ of the patients belonged to functional class III. Eighteen $(35 \%)$ were in functional class II and none in class I and IV. Postoperatively $14(27 \%)$ were in class I $(\mathrm{p}<0.002), 26(51 \%)$ in class II $(\mathrm{p}<0.001)$ and $11(22 \%)$ in class III $(\mathrm{p}<0.005)$.

A mean gradient of $46.23( \pm 2.1) \mathrm{mmHg}$ in patients with aortic stenosis decreased to a mean of $12.43( \pm 1.1) \mathrm{mmHg}$ after AVR; (p<..003). In those with AS and AR the mean gradient preoperatively decreased from a mean of $62.67 \pm 3.2) \mathrm{mmHg}$ to a mean of $11.6( \pm 2.6) \mathrm{mmHg}$ after AVR; $(\mathrm{p}<.002)$. In all patients taken together the mean gradient before AVR decreased from $55.57( \pm 1.5) \mathrm{mmHg}$ to $10.45( \pm 1.6) \mathrm{mmHg}$ after $\operatorname{AVR}(\mathrm{p}<0.0004)$.

\section{Group 2: (Table 1, 4, 5)}

There were 31 patients. Most of the patients were in the age group of 20-30. Mean age was $38.65( \pm 7.85)$. Age range was $18-74$ years. Nine patients had aortic stenosis, 7 had aortic regurgitation, and 15 had combined stenosis and regurgitation. Twenty five patients had rheumatic valve affection and 6 had degenerative disease. Most of the patients (55\%) belonged to functional class III. $35 \%$ were in functional class II. $10 \%$ in class IV and none in class $\mathrm{I}$.

In patients with aortic stenosis LVIDd significantly decreased to a postoperative mean of $4.32( \pm 0.05) \mathrm{cm}$ from a preoperative mean of $5.45( \pm 0.28) \mathrm{cm} ;(\mathrm{p}<0.033)$. For patients who had aortic valve incompetence the LVIDd registered a decrease from a mean of $5.85( \pm$ $0.08) \mathrm{cm}$ preoperatively to $4.77( \pm 0.43) \mathrm{cm}$ postoperatively; $(\mathrm{p}<0.035)$.In patients with combined aortic valve lesions, LVIDd showed a decrease from $5.75( \pm 0.24)$ to $4.86( \pm 0.3)$; $(\mathrm{p}<0.003)$. Overall in all patients, LVIDd was reduced to a mean of $4.3( \pm 0.12) \mathrm{cm}$ postoperatively from a mean of $5.88( \pm 0.26) \mathrm{cm}$ preoperatively ; $(\mathrm{p}<0.001)$

In patients with AS,LVIDs reduced from a mean of $3.4( \pm 0.25) \mathrm{cm}$ preoperatively to $2.8( \pm 0.20)$ $\mathrm{cm}$ postoperatively; $(\mathrm{p}<0.04)$. In patients with AR, LVIDs decreasedfrom a mean of $4.65( \pm$ $0.22) \mathrm{cm}$ to $4.15( \pm 0.27) \mathrm{cm} ;(\mathrm{p}<0.341)$ that was not significant. In patients with combined As and AR, LVIDs reduced from $4.74( \pm 0.12)$ to $2.84( \pm 0.21) ;(\mathrm{p}<0.004)$. Overall in group 2 , LVIDs reduced from a mean of $3.78( \pm$ $0.27) \mathrm{cm}$ to a mean of $3.08( \pm 0.14) \mathrm{cm}$; $(\mathrm{p}<0.001)$. 
In patients with aortic stenosis the preoperative EDV of a mean of $138( \pm 9.0) \mathrm{ml}$ had decreased to a postoperative value of $96( \pm 4.5) \mathrm{ml}$; $(\mathrm{p}<0.04)$ while ESV decreased from a mean of $66( \pm 5.2) \mathrm{ml}$ to $51( \pm 3.2) \mathrm{ml} ;(\mathrm{p}<0.037)$.In patients with aortic regurgitation (EDV) decreased from a mean of $165( \pm 8.13) \mathrm{ml}$ preoperatively to a mean of $87( \pm 7.5) \mathrm{ml}$ postoperatively ; $(p<0.001)$. ESV in these patients also decreased from a mean of $90( \pm$ $3.1) \mathrm{ml}$ preoperatively to $44( \pm 3) \mathrm{ml}$ postoperatively $;(p<0.002)$. For patients with combined aortic stenosis and regurgitation EDV decreased to a mean of $86( \pm 4.9) \mathrm{ml}$ from a preoperative mean of $165( \pm 6.4) \mathrm{ml}$; $(\mathrm{p}<0.0003)$. When all patients were taken together, EDV decreased from $154( \pm 5.2) \mathrm{ml}$ to $77( \pm 3.4) \mathrm{ml} ;(\mathrm{p}<0.004)$ and $\mathrm{ESV}$ from $74(\underline{3} .2) \mathrm{ml}$ to $41( \pm 5.1) \mathrm{ml} ;(\mathrm{p}<0.037)$ after AVR.

In patients who had aortic stenosis, EF increased from a preoperative mean of $46.2( \pm$ $2.5) \%$ to a value of $55( \pm 3.7) \%$ post AVR $(\mathrm{P}<0.043)$ which was not significant. Patients with aortic regurgitation only had their EF increased from a mean of $44.23( \pm 1.7) \%$ to $54.67( \pm 2.23) \% ; \quad(\mathrm{p}<0.032)$ and those with combined AS and AR had EF increased to 60 $( \pm 2.4) \%$ from a preoperative mean of 53.75 $( \pm 3.2) \% ;(\mathrm{p}<0.0013)$.When all patients were taken together, EF increased from 52.02( \pm 1.9$) \%$ to $61.23( \pm 2.1) \%$; $(\mathrm{p}<0.034)$ after AVR.

Patients with aortic stenosis had mean stroke volume (SV) of $42.63( \pm 1.6) \mathrm{ml}$ before AVR which rose to a mean of $46.55( \pm 2.4) \mathrm{ml}$ after replacement $;(\mathrm{p}<0.231)$. In those with $\mathrm{AR}$ as the only lesion, AVR caused a decrease of stroke volume from a preoperative mean of $92.6( \pm 1.8) \mathrm{ml}$ to a mean of $54.3( \pm 5.5) \mathrm{ml}$ with a p-value of $<0.002$ that was significant. In patients with combined lesions $\mathrm{SV}$ decreased from $85.45( \pm 3.9) \mathrm{ml}$ to $53.55( \pm 2.76) \mathrm{ml} ;(\mathrm{p}<0.0039)$.In all patients taken together the SV before surgery showed a mean value of $84.76( \pm 3.2)$ $\mathrm{ml}$ that decreased to $53.89( \pm 1.9) \mathrm{ml}$ after AVR ; $(\mathrm{p}<0.003)$.

Cardiac output in patients with aortic stenosis decreased from a mean preoperative value of $3.75( \pm 0.14) \mathrm{L} / \mathrm{min}$ to a mean of $3.45( \pm$ $0.2) \mathrm{L} / \mathrm{min} . \quad(\mathrm{p}<0.135) \quad$ In isolated aortic regurgitation these values after AVR decreased from a mean of $6.88( \pm 0.25) \mathrm{L} / \mathrm{min}$ to a mean of $4.25( \pm 0.35) ;(\mathrm{p}<0.015)$. In combined lesions $\mathrm{CO}$ decreased from a preoperative mean value of $7.3( \pm 0.4) \mathrm{L} / \mathrm{min}$ to a postoperative mean of $4.48 \quad( \pm 0.14) \mathrm{L} / \mathrm{min} ;(\mathrm{p}<0.002)$. For all patients taken together the $\mathrm{CO}$ showed a significant decrease from a preoperative mean of $7.5( \pm 0.59) \mathrm{L} / \mathrm{min}$ to $4.57( \pm 0.41) \mathrm{L} / \mathrm{min}$ $;(\mathrm{p}<0.0001)$.

In patients with aortic stenosis, a mean gradient of $52.14( \pm 3.1) \mathrm{mmHg}$ decreased to a mean of $11.33( \pm 1.2) \mathrm{mmHg}$ after AVR; $(p<0.0004)$.In those with AS and AR the mean gradient decreased from a mean of $62.67( \pm 3.2) \mathrm{mmHg}$ to a mean of $11.6( \pm 2.6) \mathrm{mmHg}$ after AVR; $(\mathrm{p}<0.035)$. In all patients taken together the mean gradient before AVR decreased from $55.57( \pm 1.5) \mathrm{mmHg}$ to $10.45( \pm 1.6) \mathrm{mmHg}$ after AVR $(\mathrm{p}<0.0004)$.

There was an overall improvement in the functional class of the patients with most of patients having graduated from a higher class to lower class post AVR. Preoperatively, 14 (45\%) of the patients belonged to functional class II and 17 (55\%) were in functional class III and none in class I and IV. Postoperatively $5(16 \%)$ were in class I ( $\mathrm{p}<0.003), 20(65 \%)$ in class II $(\mathrm{p}<0.031)$ and $6(19 \%)$ in class III $(\mathrm{p}<0.002)$. 
Table 1 Preoperative Demographics and Clinical Profile

\begin{tabular}{|c|c|c|}
\hline No. of Patients & $\begin{array}{c}\text { Group 1 } \\
(\mathrm{n}=51)\end{array}$ & $\begin{array}{c}\text { Group 2 } \\
(\mathrm{n}=31)\end{array}$ \\
\hline $\begin{array}{l}\text { Age (years) } \\
\text { Range } \\
\text { Mean +- SD }\end{array}$ & $\begin{array}{c}30-65 \\
40.35(+8.85)\end{array}$ & $\begin{array}{c}18-74 \\
38.65(+7.85) .\end{array}$ \\
\hline $\begin{array}{l}\text { Sex Ratio } \\
\text { Male: Female }\end{array}$ & (1) & 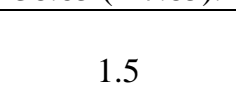 \\
\hline $\begin{array}{l}\text { Rhythm } \\
\text { Sinus } \\
\text { Atrial Fibrillation }\end{array}$ & $\begin{array}{l}38 \\
13\end{array}$ & $\begin{array}{c}25 \\
6\end{array}$ \\
\hline $\begin{array}{cc}\text { Patients with } & \\
& \text { AS } \\
\text { AR } \\
\text { Mixed AS AR }\end{array}$ & $\begin{array}{l}18 \\
10 \\
23\end{array}$ & $\begin{array}{c}9 \\
7 \\
15\end{array}$ \\
\hline $\begin{array}{c}\text { Cause of Aortic Disease } \\
\text { Rheumatic } \\
\text { Degenerative }\end{array}$ & $\begin{array}{l}41 \\
10\end{array}$ & $\begin{array}{c}25 \\
6\end{array}$ \\
\hline $\begin{array}{l}\text { NYHA functional class } \\
\text { I } \\
\text { II } \\
\text { III } \\
\text { IV }\end{array}$ & $\begin{array}{ll} & 0 \\
18 & (35 \%) \\
33 & (65 \%) \\
& 0\end{array}$ & $\begin{array}{ll} & 0 \\
14 & (45 \%) \\
17 & (55 \%) \\
& 0\end{array}$ \\
\hline
\end{tabular}

Table 2 Preoperative and Postoperative Echocardiographic Data. Group 1

\begin{tabular}{|c|c|c|c|c|c|c|c|c|c|c|}
\hline \multirow{3}{*}{$\begin{array}{l}\text { S } \\
\text { No. }\end{array}$} & \multirow{3}{*}{ Variable } & \multicolumn{3}{|c|}{ AS } & \multicolumn{3}{|c|}{ AR } & \multicolumn{3}{|c|}{$\begin{array}{ll}\text { AS } & \text { AR } \\
\end{array}$} \\
\hline & & Preop & Postop & & Preop & Postop & & Preop & Postop & \\
\hline & & & & $\mathbf{P}<$ & & & $\mathbf{P}<$ & & & $\mathbf{P}<$ \\
\hline 1 & $\begin{array}{l}\text { LVIDd } \\
\text { cm }\end{array}$ & $5.3( \pm 0.33)$ & $4.5( \pm 0.07)$ & 0.035 & $5.92( \pm 0.07)$ & $4.86( \pm 0.41)$ & 0.036 & $5.8( \pm 0.21)$ & $4.6( \pm 0.32)$ & 0.003 \\
\hline 2 & $\begin{array}{c}\text { LVIDs } \\
\text { cm }\end{array}$ & $3.6( \pm 0.23)$ & $2.9( \pm 0.3)$ & 0.042 & $4.78( \pm 0.32)$ & $4.35( \pm 0.25)$ & 0.241 & $4.54( \pm 0.17)$ & $2.87( \pm 0.25)$ & 0.004 \\
\hline 3 & $\begin{array}{l}\text { EDV } \\
\text { ml }\end{array}$ & $140( \pm 8)$ & $92( \pm 4.3)$ & 0.043 & $169( \pm 8.22)$ & $88( \pm 7.6)$ & 0.001 & $166( \pm 6.7)$ & $89( \pm 2.5)$ & 0.0003 \\
\hline 4 & $\begin{array}{l}\text { ESV } \\
\text { ml }\end{array}$ & $68( \pm 5.2)$ & $52( \pm 3.3)$ & 0.037 & $92( \pm 3.2)$ & $46( \pm 3.2)$ & 0.002 & $79( \pm 4.1)$ & $53( \pm 3.2)$ & 0.034 \\
\hline 5 & $\begin{array}{r}\mathbf{E F} \\
\%\end{array}$ & $48.3( \pm 2.3)$ & $56.02( \pm 3.8)$ & 0.013 & $46.34( \pm 1.8)$ & $56.67( \pm 2.6)$ & 0.023 & $53.27( \pm 3.4)$ & $62.05( \pm 2.1)$ & 0.001 \\
\hline 6 & $\begin{array}{c}\text { SV } \\
\text { ml }\end{array}$ & $43.23( \pm 1.6)$ & $47.56( \pm 2.2)$ & 0.231 & $91.6( \pm 1.7)$ & $52.34( \pm 5.7)$ & 0.002 & $87.24( \pm 3.8)$ & $55.45( \pm 2.98)$ & 0.0004 \\
\hline 7 & $\begin{array}{l}\text { CO } \\
\mathrm{L} / \mathrm{min}\end{array}$ & $3.8( \pm 0.12)$ & $3.5( \pm 0.23)$ & 0.135 & $6.97( \pm 0.23)$ & $4.12( \pm 0.3)$ & 0.036 & $7.34( \pm 0.42)$ & $4.45( \pm 0.12)$ & 0.002 \\
\hline
\end{tabular}

Table 3 Overall Preoperative and Postoperative Echocardiographic Data. Group 1

\begin{tabular}{|c|c|c|c|c|}
\hline Serial No. & Variable & Preoperative & Postoperative & p-< \\
\hline 1 & LVIDd cm & $5.86( \pm 0.22)$ & $4.35( \pm 0.13)$ & 0.001 \\
\hline 2 & LVIDs cm & $3.86( \pm 0.21)$ & $3.03( \pm 0.13)$ & 0.001 \\
\hline 3 & EDV ml & $166( \pm 6.7)$ & $93( \pm 5.1)$ & 0.0003 \\
\hline 4 & ESV ml & $76.31( \pm 4.1)$ & $39( \pm 3.1)$ & 0.0001 \\
\hline 5 & EF \% & $54.02( \pm 2.4)$ & $60.35( \pm 3.1)$ & 0.023 \\
\hline 6 & SV ml & $88.79( \pm 4.2)$ & $55.89( \pm 2.1)$ & 0.004 \\
\hline 7 & CO L/min & $37.56( \pm 0.66)$ & $4.54( \pm 0.43)$ & 0.0001 \\
\hline
\end{tabular}


Table 4 Preoperative and Postoperative Echocardiographic Data. Group 2

\begin{tabular}{|c|c|c|c|c|c|c|c|c|c|c|}
\hline \multirow{3}{*}{$\begin{array}{l}\text { S } \\
\text { No. }\end{array}$} & \multirow{3}{*}{ Variable } & \multicolumn{3}{|c|}{ AS } & \multicolumn{3}{|c|}{$\mathbf{A R}$} & \multicolumn{3}{|c|}{ AS AR } \\
\hline & & \multirow[t]{2}{*}{ Preop } & \multirow[t]{2}{*}{ Postop } & & \multirow[t]{2}{*}{ Preop } & \multirow[t]{2}{*}{ Postop } & & \multirow[t]{2}{*}{ Preop } & \multirow[t]{2}{*}{ Postop } & \\
\hline & & & & $\mathbf{P}<$ & & & $\mathbf{P}<$ & & & $\mathbf{P}<$ \\
\hline 1 & $\begin{array}{c}\text { LVIDd } \\
\text { cm }\end{array}$ & $5.54( \pm 0.28)$ & $4.32( \pm 0.05)$ & 0.033 & $5.85( \pm 0.08)$ & $4.77( \pm 0.43)$ & 0.035 & $5.75( \pm 0.24)$ & $4.86( \pm 0.31)$ & 0.003 \\
\hline 2 & $\begin{array}{l}\text { LVIDs } \\
\text { cm }\end{array}$ & $3.4( \pm 0.25)$ & $2.8( \pm 0.20)$ & 0.044 & $4.65( \pm 0.22)$ & $4.15( \pm 0.27)$ & 0.341 & $4.74( \pm 0.12)$ & $2.84( \pm 0.21)$ & 0.004 \\
\hline 3 & $\begin{array}{l}\text { EDV } \\
\text { ml }\end{array}$ & $138( \pm 9)$ & $4.5)^{96( \pm}$ & 0.041 & $165( \pm 8.13)$ & $87( \pm 7.5)$ & 0.001 & $165( \pm 6.4)$ & $86( \pm 4.9)$ & 0.0003 \\
\hline 4 & $\begin{array}{l}\text { ESV } \\
\text { ml }\end{array}$ & $66( \pm 5.2)$ & $51( \pm 3.2)$ & 0.037 & $90( \pm 3.1)$ & $44( \pm 3.2)$ & 0.002 & $84( \pm 2.1)$ & $40( \pm 2.7)$ & 0.029 \\
\hline 5 & $\begin{array}{r}\mathbf{E F} \\
\%\end{array}$ & $46.2( \pm 2.5)$ & $55( \pm 3.7)$ & 0.043 & $44.23( \pm 1.7)$ & $54.67( \pm 2.2)$ & 0.032 & $53.75( \pm 3.2)$ & $60( \pm 2.4)$ & 0.001 \\
\hline 6 & $\begin{array}{c}\text { SV } \\
\text { ml }\end{array}$ & $42.63( \pm 1.6)$ & $46.55( \pm 2.4)$ & 0.231 & $92.6( \pm 1.8)$ & $54.3( \pm 5.5)$ & 0.002 & $85.45( \pm 3.8)$ & $53.55( \pm 2.7)$ & 0.0039 \\
\hline 7 & $\begin{array}{l}\mathrm{CO} \\
\mathrm{L} / \mathrm{min}\end{array}$ & $3.75( \pm 0.14)$ & $3.45( \pm 0.20)$ & 0.135 & $6.88( \pm 0.25)$ & $4.25( \pm 0.35)$ & 0.015 & $7.35( \pm 0.42)$ & $4.48( \pm 0.14)$ & 0.002 \\
\hline
\end{tabular}

Table 5 Overall Preoperative and Postoperative Echocardiographic Data. Group 2

\begin{tabular}{|l|c|c|c|c|}
\hline $\begin{array}{l}\text { Serial } \\
\text { No. }\end{array}$ & Variable & Preoperative & Postoperative & p-< \\
\hline 1 & LVIDdcm & $5.88( \pm 0.26)$ & $4.75( \pm 0.12)$ & 0.001 \\
\hline 2 & LVIDs cm & $3.78( \pm 0.27)$ & $3.08( \pm 0.14)$ & 0.001 \\
\hline 3 & EDVml & $154( \pm 5.2)$ & $77( \pm 3.4)$ & 0.004 \\
\hline 4 & ESV ml & $74( \pm 3.2)$ & $41( \pm 5.1)$ & 0.037 \\
\hline 5 & EF\% & $52.02( \pm 1.9)$ & $61.23( \pm 2.1)$ & 0.034 \\
\hline 6 & SVml & $84.76( \pm 3.2)$ & $53.76( \pm 1.9)$ & 0.003 \\
\hline 7 & CO L/min & $7.5( \pm 0.59)$ & $4.57( \pm 0.41)$ & 0.0001 \\
\hline
\end{tabular}

Table 6 Comparison of Overall Postoperative Echocardiographic Data. Group $1 \&$ Group 2

\begin{tabular}{|c|c|c|c|c|}
\hline Serial No. & Variable & Group 1 & Group 2 & $\mathbf{p}-<$ \\
\hline 1 & LVIDdcm & $4.35( \pm 0.13)$ & $4.75( \pm 0.12)$ & 0.145 \\
\hline 2 & LVIDs cm & $3.03( \pm 0.13)$ & $3.08( \pm 0.14)$ & 0.252 \\
\hline 3 & EDVml & $93( \pm 5.1)$ & $77( \pm 3.4)$ & 0.275 \\
\hline 4 & ESV ml & $39( \pm 3.1)$ & $41( \pm 5.1)$ & 0.272 \\
\hline 5 & EF\% & $60.35( \pm 3.1)$ & $61.23( \pm 2.1)$ & 0.341 \\
\hline 6 & SVml & $55.89( \pm 2.1)$ & $53.76( \pm 1.9)$ & 0.175 \\
\hline 7 & CO L/min & $4.54( \pm 0.43)$ & $4.57( \pm 0.41)$ & 0.541 \\
\hline
\end{tabular}

\section{Discussion}

Aortic valve surgery has come a long way since the first reported experiment of aortic valvotomy $^{(1)}$. Any alteration in the normal aortic orifice size of 2.5 to $3 \mathrm{~cm}^{2}$ produces variety of haemodynamic changes from either stenotic, regurgitant or combined lesions. With the invention of earliest prosthetic valves by Hufnagel to modern day more compatible aortic prostheses and Trans catheter Aortic Valve Implantation (TAVI), the treatment of aortic valve disease has been revolutionised. Even though left ventricular systolic and diastolic functions improve after surgery, the reduction in left ventricular mass is most often moderate and unpredictable ${ }^{(2)}$ and depends upon the extent of myocardial degeneration and related 
reduction in left ventricular reserve that has set in before $\mathrm{AVR}^{(3)}$.

Studies have shown that AVR causes reduction in the LVIDd and LVIDs that were previously abnormal ${ }^{(4,5,6)}$. We in our study found that there was a significant improvement in left ventricular dimensions both in systole and diastole after AVR when all the patients in one group were considered. (Table 3,5). However, when studied separately we found that reduction in LVIDs in patients with AR was not significant in comparison to patients with AS or mixed AS and AR in both the study groups (Table 2,4). The reason could be more myocardial degenerative changes that might have been caused by combined concentric and eccentric hypertrophy of left ventricle in patients with pure AR. Also the process of remodeling of left ventricle post AVR is gradual and our study to determine the recovery after one year only could be too short a time period. However, while comparing the parameter between two groups, we found that the type of prosthetic valve- whether bileaflet or monoleaflet, does not influence the outcome $\mathrm{p}<.252$. (Table 6).

An important parameter to determine preload and ejection fraction is Left Ventricular End Diastolic volume (EDV) and End Systolic Volumes (ESV). With the improvement of haemodynamics around the valve after AVR, there is a decrease in the EDV and ESV as both of them show regression towards normal values. However this reduction is slightly more, though insignificant, in case of AS than in AR probably because concentric hypertrophy in AS involves increase in number of cardiac muscle fibres as in contrast to $\mathrm{AR}$ where there is increase in the length of muscle fibres. This therefore preserves the cardiac muscle strength that manifests with more emptying of ventricle when the obstruction is removed. Chronic volume overloading in AR causes basic alteration in architecture and fibre malalignment in ventricular wall that influences the post operative function ${ }^{(9)}$. Earlier studies have also determined that replacement of a diseased aortic valve causes reduction of EDV and ESV which significantly improves left ventricular function ${ }^{(3,4,7,8)}$.In our series of patients in two groups, the decrease in EDV and ESV was comparable and did not show any significant difference with a $p$-value of $(p<0.275)$ and $(p<0.272)$ respectively implying that the make of the valve replaced at aortic position has little bearing on this (Table 6).

Ejection Fraction (EF) is the most common and reliable parameter to determine the adequate functioning of the ventricle. The objective assessment of left ventricular ejection fraction appears to be a useful tool in clinical management of patients having aortic valve replacement ${ }^{(10)}$. Aortic valve disease causes decrease in the percentage of blood that is ejected from left ventricle at the end of a contraction altering haemodynamics. Robert et al studied a series of 12 consecutive patients of AS undergoing AVR with severely depressed EF. They found that EF after surgery rose significantly from $13 \%$ to $45 \%{ }^{(7)}$. Franz Schwarz and colleagues studied a series of 128 patients. They also reported that EF after AVR increased significantly in both AS and AR patients ${ }^{(11)}$. Replacement of the diseased native valve by a prosthesis improves ejection fraction with tendency towards normalization. Whatever the lesion of the aortic valve, there is a significant increase in ejection fraction post AVR and we found that this does not depend on type of mechanichal prosthesis used as the difference in $\mathrm{EF}$ in our two groups postoperatively was statistically insignificant $(\mathrm{p}<0.175$, Table 6$)$

In patients with aortic stenosis, mean stroke volume (SV) rose after replacement. In those with AR as the only lesion, AVR caused a decrease of stroke volume in patients of both the groups. Simon et al in their series of 10 patients with severe AR who had decreased stroke volumes and cardiac output before surgery found that almost all patients had normal values of both stroke volumes and cardiac output after $\mathrm{AVR}^{(12)}$ David Harpoleetal showed that mean 
preoperative cardiac output decreased from 7.5 (2.2) $\mathrm{L} / \mathrm{min}$ to 6.7 (+- 2.3) $\mathrm{L} / \mathrm{min}, 3$ months after surgery ${ }^{(13)}$ When we compared the two groups, there was no statistically significant difference in this variable after valve replacement $(\mathrm{p}<0.175$, Table 6).

In our study, there was an overall comparable improvement in the functional class of the patients in both the groups with most of patients having graduated from a higher class to lower class post AVR. Robert P Croke et al, James D et al, Seppo Let al, Clark et al, have in their respective studies reported similar results and shown an overall improvement in the NYHA functional class $(7,14,15,16)$

\section{Conclusion}

We conclude from our study that replacement of diseased native aortic valve by a prosthesis helps in restoration of left ventricular functions towards normal expressed by improvements in cardiac echocardiographic parameters. Functional class was improved as a consequence of improved left ventricular pump function. A consistent regression of left ventricular dilatation and hypertrophy was noted even in patients who did not show any significant improvement in their ejection fraction. However it was significant to note that the type of prosthetic valve whether monoleaflet or bileaflet did not have any effect on the final out come on the remodeling and restoration of ventricular functions.

\section{Conflict of Interest: None}

Disclosure: We the authors have no financial disclosure to make as we did not receive any funding from any quarter.

One consultant did not agree to participate in the study hence his patients were not included.

\section{References}

1. Smitty HG, Parker EF. Experimental aorticvalvotomy, preliminary report. Surg Gynaecol Obstet 1947; 34:625
2. Miller GAH, Kirklin JW, Swan HJC. Myocardial function and left ventricular volumes in Acquired valvular insufficiency. Circulation 1965;31:374

3. Kennedy JW, Doces J, Stewart DK. Left ventricular function before and following aortic valve replacement. Circulation 1977;56:944

4. Pela G, La Canna G, Metra M. Long term changes in left ventricular mass, chamber size and function after aortic valve replacement in patients with severe aortic Stenosis and depressed ejection fraction. Cardiology 1997;88 (4);315-22

5. Tarasoutchi F, Filho JP, Cardoso LF, Protasio L, et al . Symptoms, left ventricular function and timing of valve replacement surgery in patients with aortic regurgitation. American Heart Journal 1999;138:477-85

6. Skarvan K, Zuber M, Seeberger M, Stulz P. Immediate effects of aortic valve replacement on left ventricular function and its determinants. European Journal of Anaesthesiology 1999;16:65968.

7. Robert P, Roque Pifarre, Henry Sullivan. Reversal of advanced left ventricular dysfunction following aortic valve replacement for aortic Stenosis. The annals of Thoracic Surgery 1977; 24(1):38

8. Martin JS, Plappert T, Speigel A, et al . Early postoperative changes in left ventricular

chamber size, architecture and function in aortic stenosis and aortic regurgitation and their relation to intraoperative changes in afterload: a prospective two dimensional echocardiographic study. Circulation 1987; 76(1):77-89.

9. Stephen J, Micheal V, Richard Gorlin. Cardiac shape and function in aortic valve disease: 
Physiologic and clinical implications. The American Journal of Cardiology 1977;39:170.

10. Santinga JT, Kirsh MM, Brady TJ, Thrall $\mathrm{J}$, pitt B. Radionuclide angiography in evaluation of left ventricular function following aortic valve replacement. The annals of Thoracic Surgery 1981;31(5): 409.

11. Franz $S$, Willem F, Michael $S$ et al. Impaired left ventricular function in chronic aortic valve disease: Survival and functios after replacement by BjorkShiley Prosthesis. Circulation 1979; 60(1): 48.

12. Simon Jk, Mant H, Richard ER. Circulatory changes in severe aortic regurgitation before and after surgical correction. The American Journal of Cardiology 1971; 28: 442.

13. Harpole DH, Jones RH. Serial assessment of ventricular performance after valve replacement for aorticstenosis. Jthorac Cardiovasc Surg 1990; 99: 645-50.

14. James D, Edward A, Sudhakar R et al. Effect of preoperative ejection fraction on survival and haemodynamic improvement following aortic valve replacement. Circulation 1978; 58 (6): 175.

15. Seppo L, Juha T, Matti R. Effect of aortic valve replacement on the leftventricle. Scand J Thor Cardiovasc Surgery 1979; 13:249-54.

16. Clark DG, Mcnulty JH, Rahimatoola SH. Valve replacement in aortic insufficiency with LV dysfunction. Circulation 1980;61:411. 